\title{
\#EdTechHub
}

Realising the potential of technology in education

\section{A five-part education response to the COVID-19 pandemic}

Dr Björn Haßler, Abdullah Khalayleh, Chris McBurnie

EdTech Hub, https://edtechhub.org

Helpdesk Response No. 05

2020-05-26

Version 2

DOI: $10.5281 /$ zenodo.3756012 


\section{About this document}

Recommend Haßler, B., Khalayleh, A., \& McBurnie, C. (2020). A five-part education response ed citation. to the COVID-19 pandemic (EdTech Hub Helpdesk Response No. 5).

https://doi.org/10.5281/zenodo.3756012. Available at https://docs.edtechhub.org/lib/JLEWADHF. Available under Creative Commons Attribution 4.0 International, https://creativecommons.org/licenses/by/4.0/.

Licence. Creative Commons Attribution 4.0 International https://creativecommons.org/licenses/by/4.0/.

You - dear readers - are free to share (copy and redistribute the material in any medium or format) and adapt (remix, transform, and build upon the material) for any purpose, even commercially. You must give appropriate credit, provide a link to the license, and indicate if changes were made. You may do so in any reasonable manner, but not in any way that suggests the licensor endorses you or your use.

\section{Creative N/A \\ Commons \\ Acknow- \\ ledgement}

Identifiers. 2405685:JLEWADHF; 2129771:XKGV4EYL; 10.5281/zenodo.3756012.

Internal use. g/d/1fuTCw29SFw0mhC7YYRIhHZaDsjFvjCMrwOzVNQDTSzE

Notes. This working paper does not represent the consensus of the EdTech Hub, but rather the evidence-informed opinion of the author(s).

You can contact the EdTech Hub here: https://edtechhub.org/hello/.

Future updates to this paper will be available here: 10.5281/zenodo.3756011.

Diagrams available as PDF at XXX and as LucidChart here https://app.lucidchart.com/documents/edit/b5713a17-bede-4596-b2eb-fd077 adaab62/f_dRiUFwn9w8. 


\section{Table of contents}

$\begin{array}{lr}\text { Executive Summary } & 4\end{array}$

$\begin{array}{lr}\text { 1. Introduction } & 5\end{array}$

$\begin{array}{ll}\text { 2. Gather crucial data } & 7\end{array}$

Tool 1. Crucial data gathering 1

Tool 2. Quick availability assessment of technology 10

A. Radar chart on technologies $\quad 10$

B. Radar chart on technologies: (very) high-income countries $\quad 11$

C. Radar chart on technologies: high- vs. middle-income countries 12

D. Radar chart on technologies: high- vs. low-income countries 13

E. Radar chart on technologies: layering of populations within one country 14

Developing an equitable response - when most children are offline 15

$\begin{array}{ll}\text { 3. Organise your workforce } & 17\end{array}$

$\begin{array}{ll}\text { Tool 3. Organise your workforce } & 18\end{array}$

$\begin{array}{ll}\text { A. Ministry staff } & 18\end{array}$

$\begin{array}{ll}\text { B. Teachers } & 18\end{array}$

$\begin{array}{ll}\text { C. Parents } & 18\end{array}$

D. Institutional partners 18

4. Build a sense of community between students, families and schools 19

5. Provide teaching and learning materials $\quad 19$

Tool 4. Approaches for student learning under COVID-19 20

Approach 1. Radio $\quad 20$

$\begin{array}{ll}\text { Approach 2. TV } & 24\end{array}$

Approach 3. Basic digital and online $\quad 27$

Approach 4. Extended digital resource use and online access 29

6. Prepare for what happens after the COVID-19 pandemic 30

$\begin{array}{ll}\text { References } & 31\end{array}$ 


\section{Executive Summary}

In early March, many countries began to close schools to slow the spread of coronavirus. Education leaders have subsequently launched rapid response programmes, implemented measures to support system recovery and explored long-term reforms. This paper proposes a five-part approach to guide education leaders through this process.

\section{Gather crucial data}

Education leaders should use current education data where possible to shape their response to COVID-19. Data should be used to understand the local policy environment, map existing infrastructure and identify the modes of education that reach the widest number of learners. In particular, education leaders need to explore the extent to which different populations within their country have access to devices in the home. Governments need to continuously collect data to monitor the impact of their response and adapt their plans accordingly.

\section{Organise the workforce}

Governments need to organise ministry staff, teachers, parents and institutional partners as part of the COVID-19 response. Important aspects of this step include preparing ministry staff to work from home and setting up communication channels with different stakeholders. In this process, governments should identify each group's preferred mode of communication.

\section{Build a sense of community between students, families and schools}

Education leaders should facilitate communication and collaboration between teachers and families to ensure children receive tailored instruction. Education leaders need to ensure that caregivers are ready to facilitate home-based learning. Evidence from previous health crises indicates that students do not benefit from self-study materials without adult or peer support.

\section{Provide teaching and learning materials}

Education leaders need to develop a multi-pronged, sequenced strategy to address the educational impact of COVID-19. This type of response may initially use a combination of radio and television to deliver educational content before phasing in paper-based materials. This strategy needs to acknowledge that most learners in low- and middle-income countries are offline and will have limited or no access to digital learning resources.

\section{Prepare for what happens after the COVID-19 pandemic}

The COVID-19 education response needs to consider the pandemic's medium- to long-term implications. Education leaders should use the current hiatus to strengthen the quality of education delivery ahead of schools reopening. Education leaders could, for example, develop an open curriculum or a national teacher professional development programme. 


\section{Introduction}

While the COVID-19 pandemic will continue to evolve and impact society and education systems in ways that are difficult to predict today, it is imperative to act now. Based on best evidence, we must make decisions that can mitigate the pandemic's impact on education and, particularly, the learning outcomes of marginalised students.

The World Bank Group's President, David Malpass, recently raised a number of important points on the breadth and speed of our initial response, measures to accelerate system recovery, and future structural reforms. ${ }^{1}$ We can extract three themes to apply to education: response, recovery, reform.

1. Response: Governments must implement an immediate education response that incorporates economic and health considerations, particularly for the most marginalised. The immediate response is the first stage in a recovery sequence.

2. Recovery: Governments have to consider how to support a return to full schooling and how to address crisis-related learning gaps to facilitate medium-term recovery.

3. Reform: The recovery sequence must lead to education reform. In many low-income countries, education systems have struggled in their progress towards equitable quality education (Sustainable Development Goal 4). Governments need to use the COVID-19 pandemic recovery effort to promote system reform and improvements.

Building on this helpful framework, we put forward a five-part approach to mitigate the educational impact of the pandemic in both the short and medium term. The five parts are not mutually exclusive: they reinforce each other, overlap in time, and form a progressive strategy. However, each of the five parts presents its own challenges and therefore warrants individual consideration.

\footnotetext{
1 i David Malpass (2020); Remarks by World Bank Group President David Malpass on G20 Finance Ministers Conference Call on COVID-19
} 
1. Gather crucial data (initial and continuous)

What resources do students and teachers have access to? How many students and teachers have we reached?

\begin{tabular}{|l|l|l|l|}
\hline \multicolumn{1}{|c|}{$\begin{array}{l}\text { 2. Organise the } \\
\text { workforce }\end{array}$} & $\begin{array}{l}\text { 3. Build a sense of } \\
\text { community } \\
\text { between } \\
\text { students, } \\
\text { families and } \\
\text { schools }\end{array}$ & $\begin{array}{l}\text { 4. Provide teaching } \\
\text { and learning } \\
\text { materials }\end{array}$ & $\begin{array}{l}\text { 5. Prepare for what } \\
\text { happens after } \\
\text { the CoviD-19 } \\
\text { pandemic }\end{array}$ \\
\hline $\begin{array}{l}\text { How can teachers, } \\
\text { ministry staff and } \\
\text { education officials } \\
\text { work remotely? }\end{array}$ & $\begin{array}{l}\text { How can we connect } \\
\text { students with their } \\
\text { teachers and schools? }\end{array}$ & $\begin{array}{l}\text { How can we deliver } \\
\text { materials to teachers } \\
\text { and students? }\end{array}$ & $\begin{array}{l}\text { System reform and } \\
\text { strengthening, } \\
\text { including preparations } \\
\text { for students to return } \\
\text { to school }\end{array}$ \\
\hline
\end{tabular}




\section{Gather crucial data}

Governments should base their decisions on current education data where possible. However, we realise that accessing relevant data is not necessarily straightforward and this aspect should not block other elements of system response, recovery, reform. Crucial data relating to education includes:

- Governments' COVID-19 policy response. What are the measures taken by the government to address COVID-19? Are all schools closed yet? Are they closed in all areas? Is there a strict lockdown? If not, will there be one in the near future? For how long do they plan to close schools?

- Population device and internet availability rates. This data is typically available from network providers / operators, Ministries of ICT or governmental telecom regulators. When possible, this data should be broken down geographically and demographically. Otherwise, the most marginalised will be excluded. Such data includes:

$\circ$ internet availability

- device availability (e.g., laptops, smartphones, basic phones, radios, TVs)

- geography of device and internet availability rates

- device availability according to education level and / or socio-economic status

- What infrastructure is already in place that might support remote learning?

- Are there dedicated radio or TV channels for education? Can governments repurpose existing channels for education delivery?

- Does the public education system already have one or more learning management systems (software for managing the delivery and administration of education programmes) in place?

- Are there governmental and non-governmental institutions with readily available learning content? Are these available in national and local languages?

- Is there a policy for e-learning / technology use in education already in place? How does it guide practices regarding the use of technology in education?

- Monitor ongoing impact of COVID-19 responses. Monitoring responses to dealing with COVID-19, particularly education responses, will be crucial. Approaches will need to change based on what's appropriate to evolving contexts. Current education responses need to be continuously reviewed to ascertain whether they are adequately supporting out-of-school learning. This involves in-depth data gathering, e.g., not just looking at website log-ins, but looking at usage data.

- Monitor the side effects of school closures. School closures can impact children's health and social lives as well as education. For example, this World Food Programme map indicates how COVID-19 has disrupted school feeding programmes across the world. Are there non-academic services that need to be delivered that are usually distributed through schools? 


\section{Tool 1. Crucial data gathering}

\begin{tabular}{|c|c|c|}
\hline Topic & Questions & Source \\
\hline \multirow{6}{*}{$\begin{array}{l}\text { Access (by } \\
\text { geography / } \\
\text { demographic } \\
\text { if possible; } \\
\text { see Tool 2) }\end{array}$} & $\begin{array}{l}\text { To what extent does the population have access to } \\
\text { the Internet? }\end{array}$ & \multirow{6}{*}{$\begin{array}{l}\text { Network providers / } \\
\text { operators, Ministries } \\
\text { of ICT or } \\
\text { governmental } \\
\text { telecom regulators }\end{array}$} \\
\hline & To what extent are laptops available? & \\
\hline & To what extent are smartphones available? & \\
\hline & To what extent are basic phones available? & \\
\hline & To what extent are radios available? & \\
\hline & To what extent are TVs available? & \\
\hline \multirow{5}{*}{$\begin{array}{l}\text { Existing } \\
\text { resources }\end{array}$} & $\begin{array}{l}\text { What are existing dedicated radio or TV channels for } \\
\text { education? Which existing channels could } \\
\text { governments repurpose for education delivery? }\end{array}$ & Ministry of Education \\
\hline & $\begin{array}{l}\text { Does the public education system already have one } \\
\text { or more learning management systems (software for } \\
\text { managing the delivery and administration of } \\
\text { education programmes) in place? If so, which } \\
\text { system(s)? }\end{array}$ & Ministry of Education \\
\hline & $\begin{array}{l}\text { Are there communication tools in place to reach out } \\
\text { to headteachers / principals, teachers, potentially } \\
\text { parents or even students? (e.g., SMS portals, sending } \\
\text { SMS via mobile network operators, Whatsapp } \\
\text { groups, contact information database) }\end{array}$ & Ministry of Education \\
\hline & $\begin{array}{l}\text { Is there a policy for e-learning / technology use in } \\
\text { education already in place? }\end{array}$ & Ministry of Education \\
\hline & $\begin{array}{l}\text { What learning content do local governmental and } \\
\text { non-governmental institutions have that is ready for } \\
\text { distribution? }\end{array}$ & $\begin{array}{l}\text { Ministry of } \\
\text { Education, Desk } \\
\text { Research }\end{array}$ \\
\hline $\begin{array}{l}\text { Side effects } \\
\text { of school } \\
\text { closure }\end{array}$ & $\begin{array}{l}\text { Are there essential non-educational programmes } \\
\text { delivered via schools that will be at risk (e.g., feeding } \\
\text { programmes)? }\end{array}$ & Ministry of Education \\
\hline
\end{tabular}


How does school closure impact at-risk

communities? (e.g., increases in gender-based

violence (GBV), teenage pregnancies, drop-out rates,

child labour, students with health risks) 


\section{Tool 2. Quick availability assessment of technology}

\section{A. Radar chart on technologies}

This radar chart allows policymakers to estimate and visualise the population's access to five technologies (radio, TV, non-smartphone, smart phone, laptop). For non-smartphones (SMS, interactive voice), smartphones (mobile internet), and laptops (unmetered internet) the diagram shows features those technologies may or may not include.

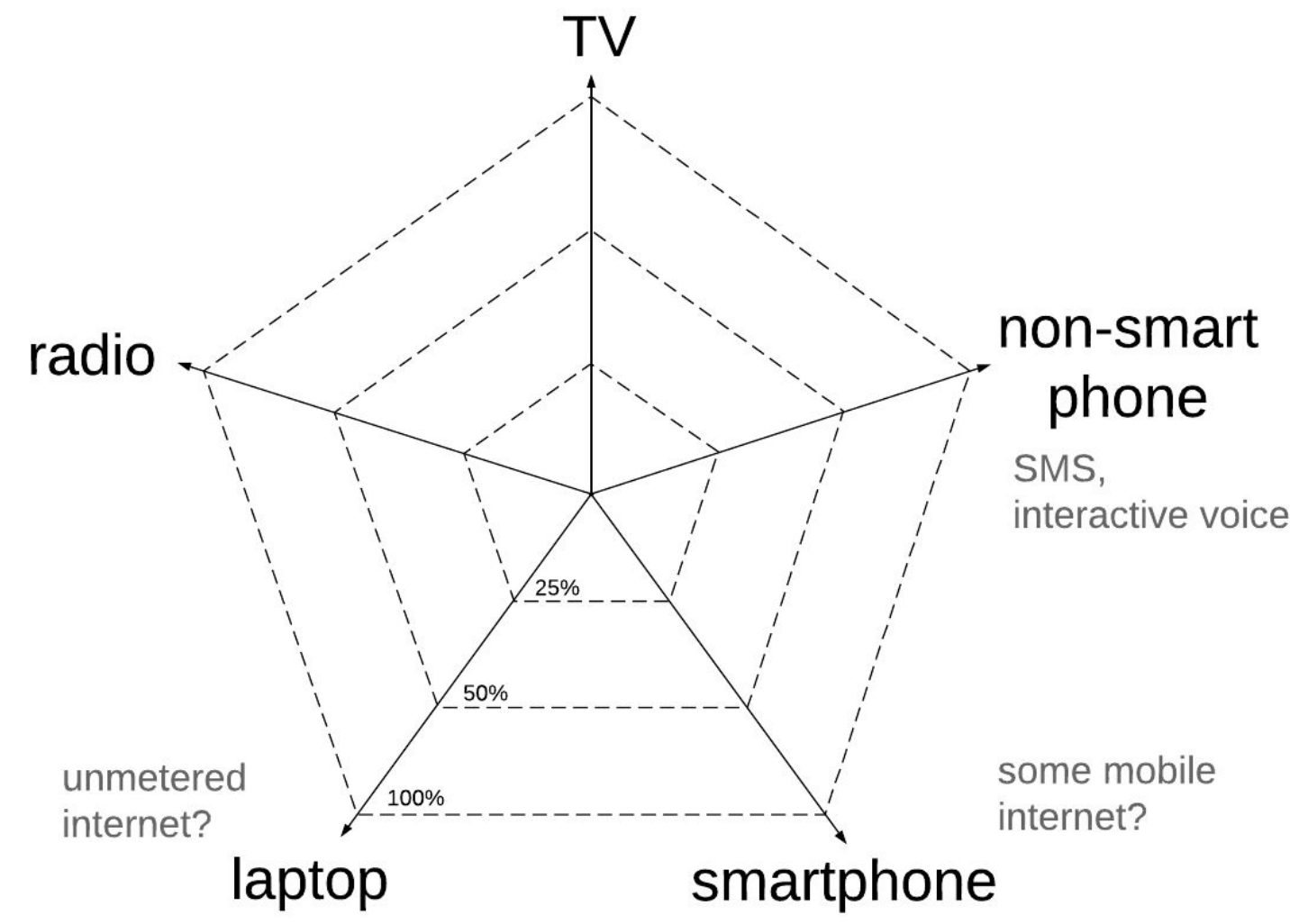

Instructions. Use current education data (see Section 2) to estimate the percentage of households in your nation that have access to a device (e.g., radio or a non-smartphone). Bear in mind that this figure will not represent the number of children in your nation that may have access to such a device. For example, while a household may have one TV, TV time may be shared between more than one child.

UNESCO and the EdTech Hub provide an overview of data on the availability of technology in a number of countries in sub-Saharan Africa (UNESCO Institute for Statistics, 2015; Taddese, 2018; Upadhyay, 2018). 


\section{B. Radar chart on technologies: (very) high-income countries (illustrative)}

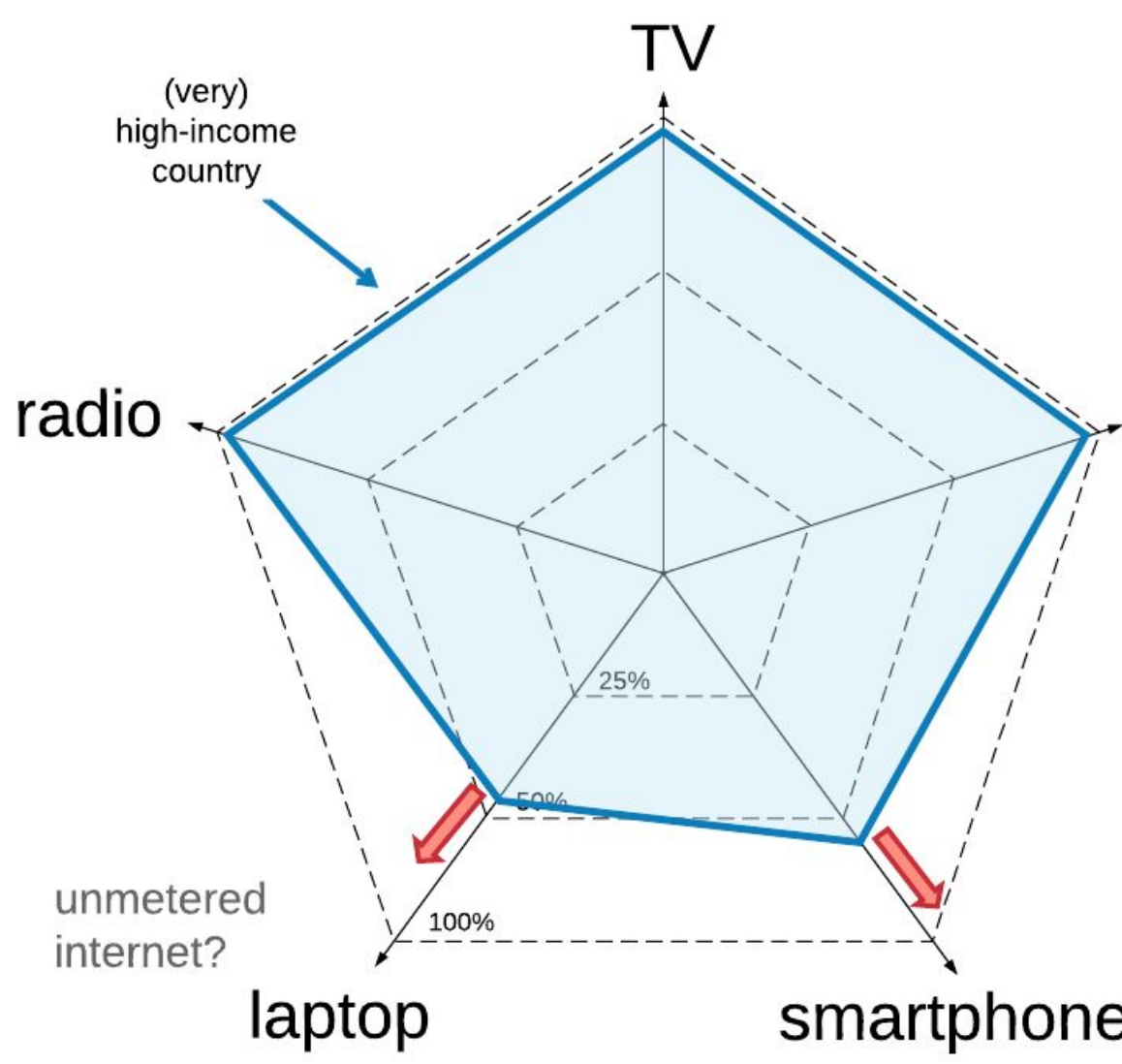

non-smart phone SMS, interactive voice

some mobile internet?

This diagram illustrates the values for a (very) high-income country. While this will vary between countries, it seems reasonable to assume that:

- All households have access to TV and likely a radio (or access to radio via internet).

- Many households (above 50\%) will own at least one smartphone. It may well be the case that almost all households have smartphones. Households without smartphones may be those with elderly residents.

- The number of (non-)smartphones per household may be much higher than one per household. For example, some households may have one (non-)smartphone per person or may have older (unused) smartphones.

- Not all households have access to a laptop. Even in the UK, we know that there are households without laptops.

The small red arrows indicate possible shifts to account for the purchasing power in (very) high-income countries. It is likely that households are able to acquire additional devices. Also, the government may be able to support the acquisition of certain devices (such as laptops in the UK; we will return to this below). ${ }^{2}$

2 iCoughlan (2020). 


\section{Radar chart on technologies: high- vs. middle-income countries (illustrative)}

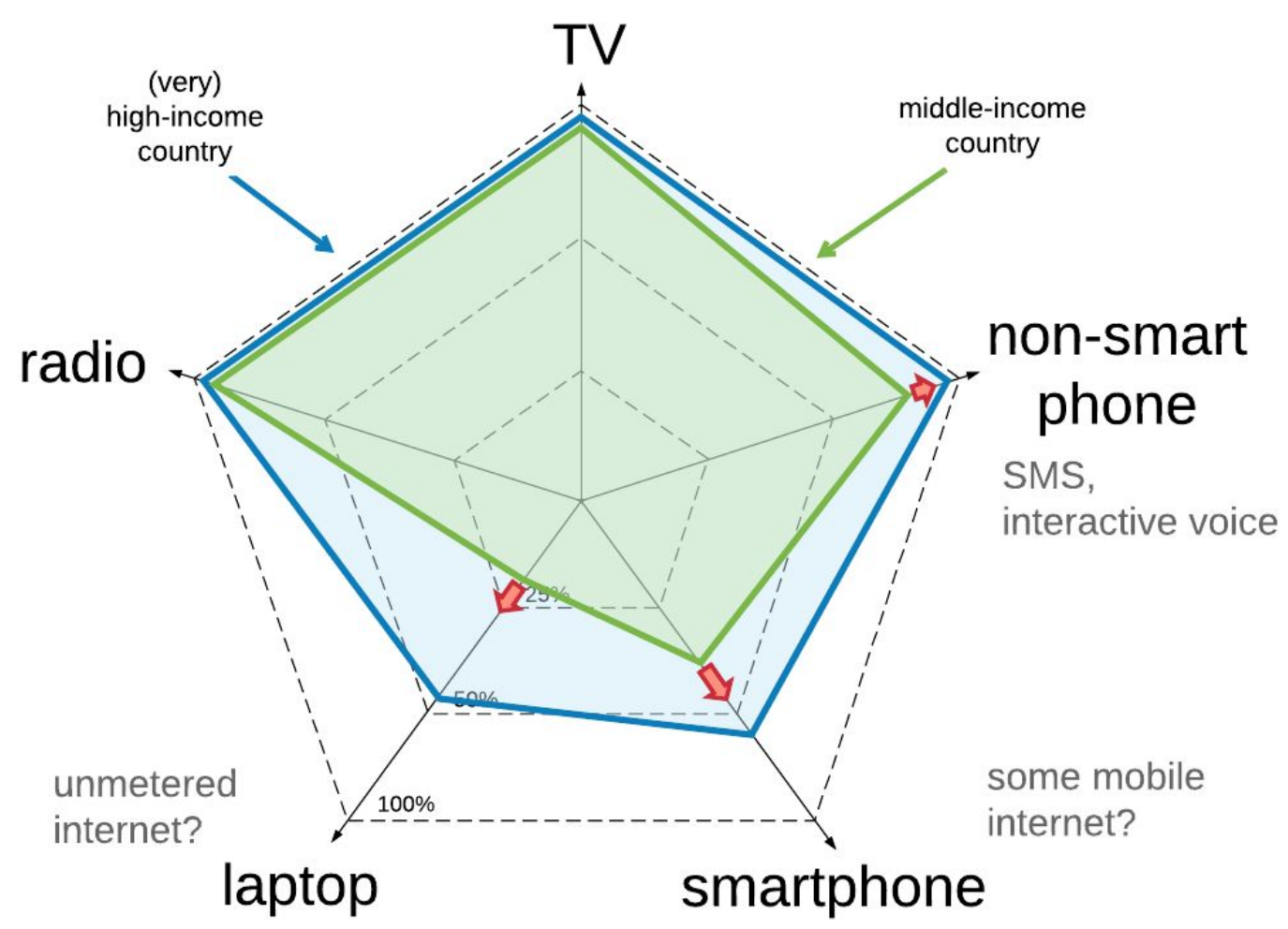

This diagram illustrates the values for a high- / middle-income country (green) with the values for a (very) high-income country (blue). While this will vary between countries, it seems reasonable to assume that:

- All households have access to radio and almost all households have a TV.

- Most households have a non-smartphone. Where there is no non-smartphone, households should be able to acquire one.

- A lower number of households have smartphones although it may still be possible for more households to acquire a smartphone.

- The number of households with laptops will be quite low.

We note that there will be significant variance between urban and rural areas. Urban areas are likely to be closer to the (very) high-income country curve (in blue), while rural areas are likely to be closer to (or below) the green curve. Even if a household has access to a device, the use of that device may not be shared equally among household members. Depending on the culture, girls / women (e.g, sub-Saharan Africa) or boys (e.g., Caribbean) may be disadvantaged (^Psaki, et al., 2018); ^

The small red arrows indicate possible shifts to account for the purchasing power in middle-income countries. 


\section{Radar chart on technologies: high- vs. low-income countries (illustrative)}

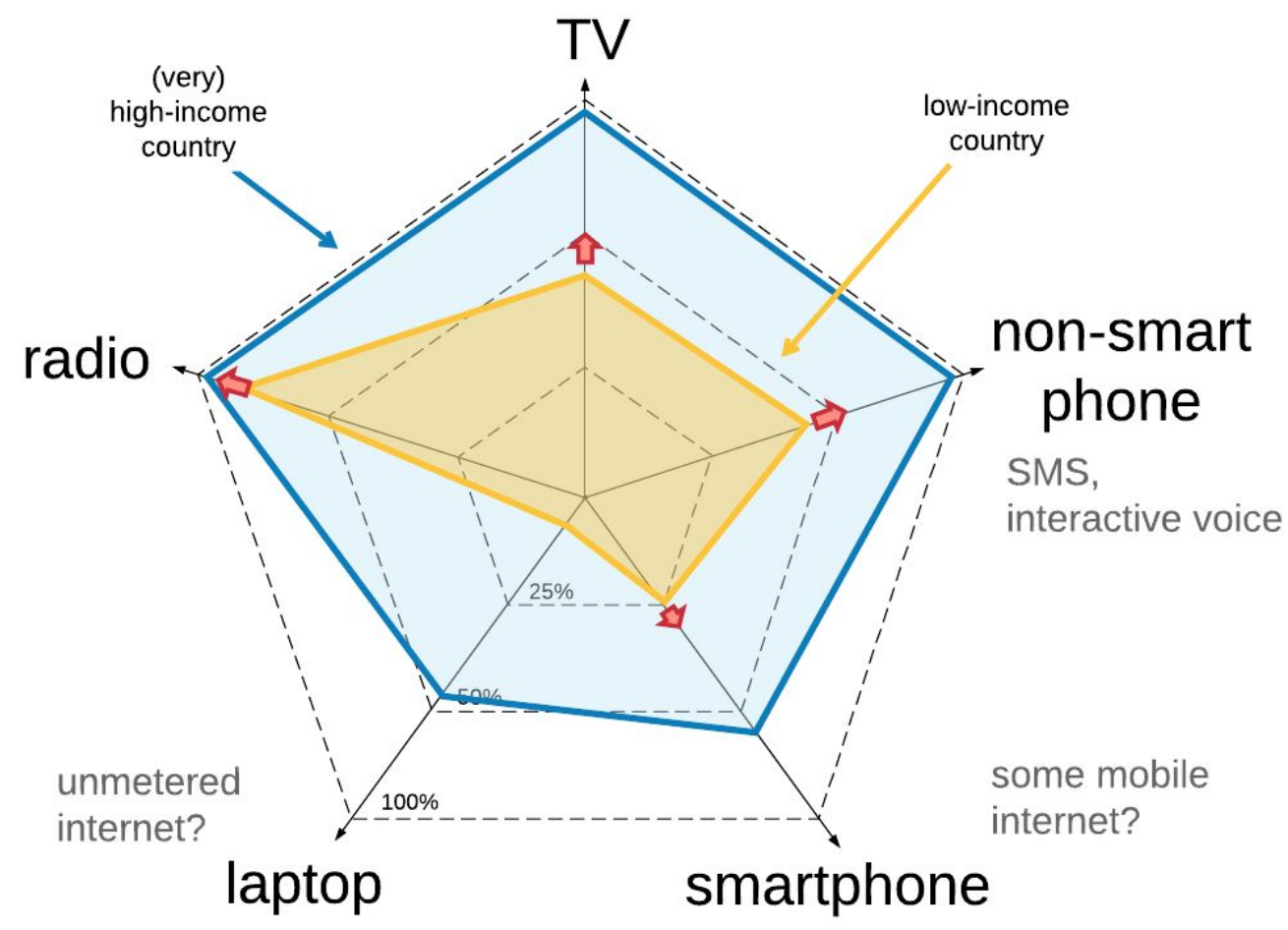

This diagram compares the values for a low-income country (orange) with the values for a (very) high-income country. In low-income countries, we expect:

- While less than $100 \%$ of households have one radio, many households can use and access radios.

- A fair number of households have TVs and non-smartphones.

- The number of households with smartphones will be low, and the number of households with laptops will be even lower.

- Significant variance between urban and rural areas. Urban areas are likely to be closer to the (very) high-income country curve (in blue), while rural areas are likely to be closer to (or below) the orange curve

- Even if a household has access to a device, the use of that device may not be shared equally available among household members. Depending on the culture, girls / women or boys may be disadvantaged.

The small red arrows indicate possible shifts to account for purchasing power in low-income countries. While some improvements (radio, TV, non-smartphones) may be possible, mass acquisition of smartphones or even laptops would appear very unlikely. 


\section{E. Radar chart on technologies: layering of populations within one country (illustrative)}

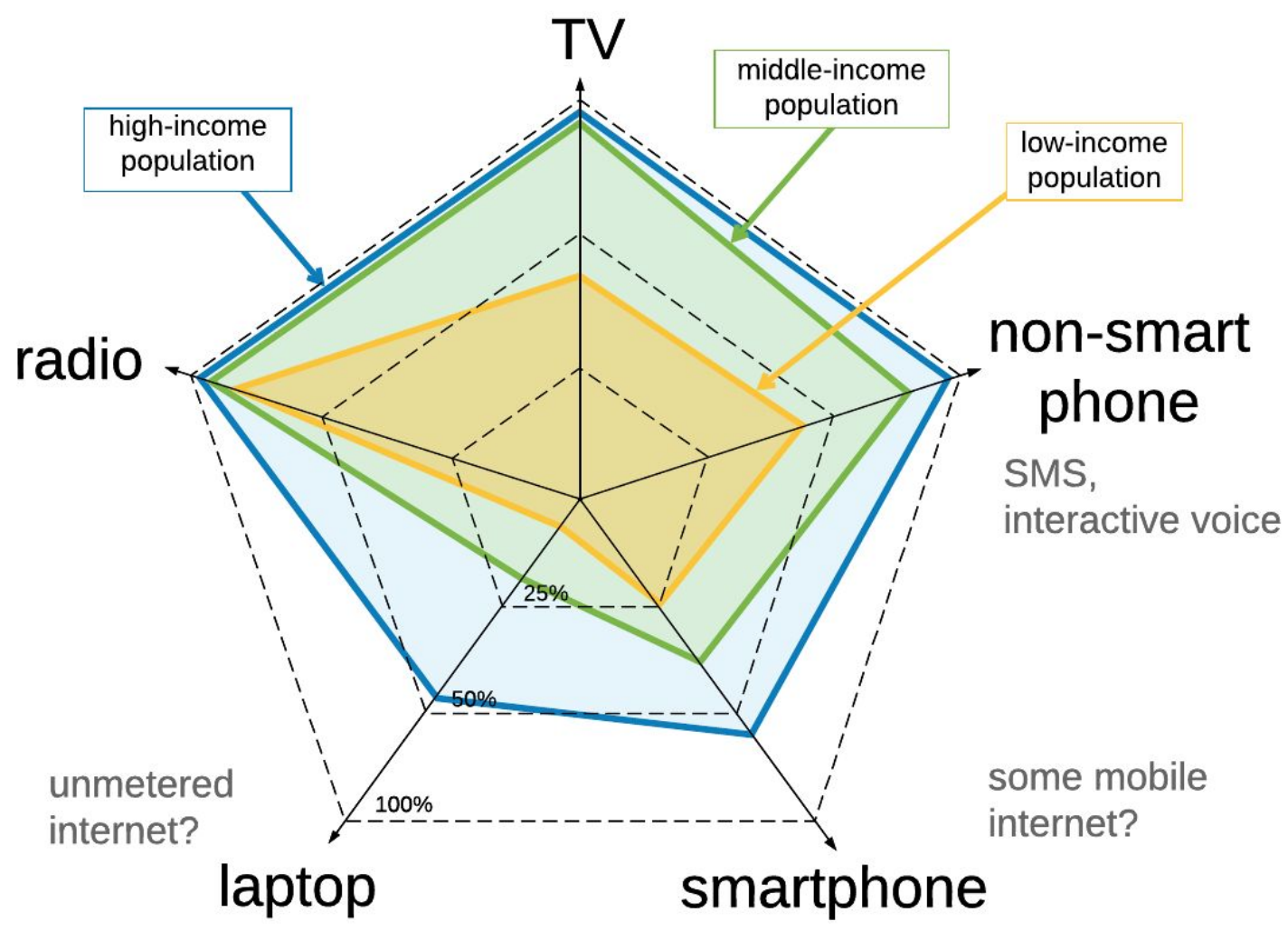

In this diagram, we consider different populations together in one nation. For example, in a low-income country, the majority of the population will be a low-income population.

However, there will be some middle-income citizens (e.g., teachers and other professionals) and some high-income citizens. In a middle-income country, the majority of the population will be middle-income although there may well be a low-income population of appreciable size. 


\section{Developing an equitable response - when most children are offline}

Having used current data to assess the average affordances of different nations by income (Tool 2, A-D) and having overlaid different populations (Tool 2, E), we will now look at the distribution of different populations within one country. The schematic diagram below shows the distribution of populations within three types of countries (high-income, middle-income, low-income).

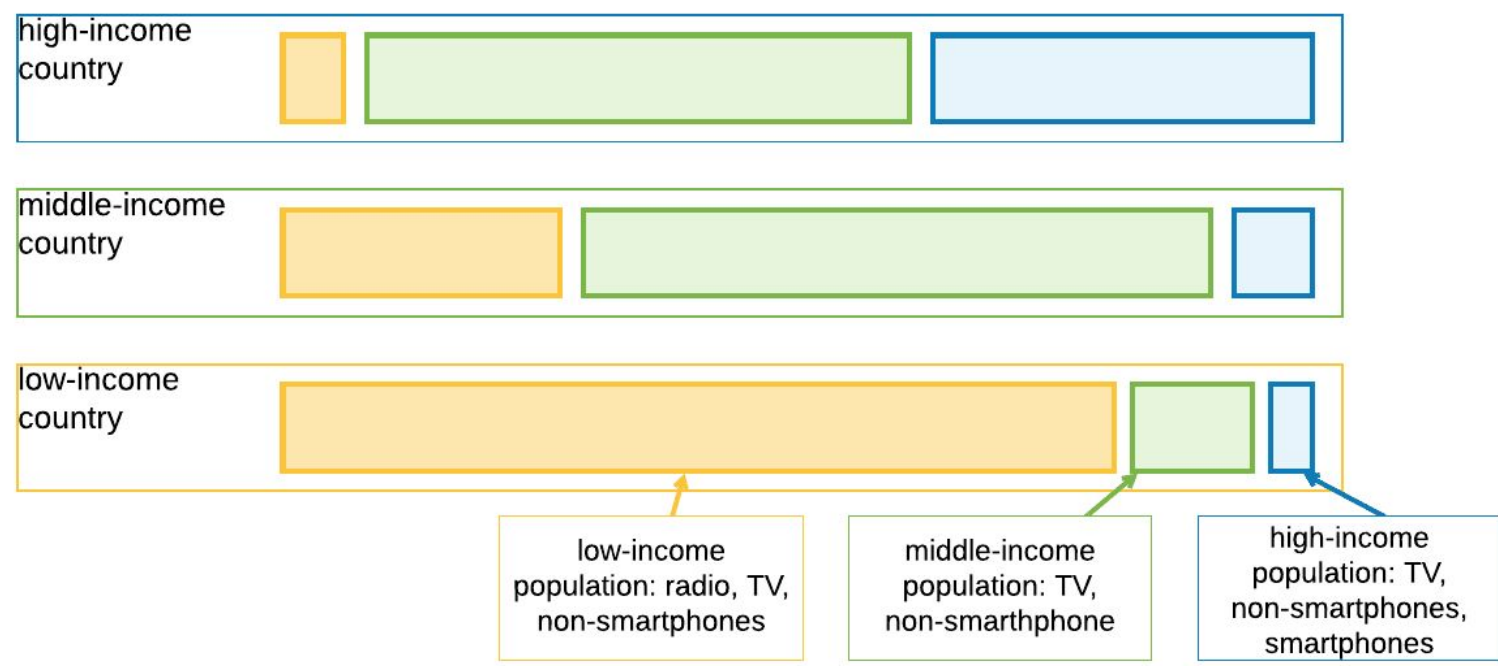

Perhaps the most notable takeaway from the diagram is that in a low-income country, a response based on students' access to the internet and / or smartphones (i.e., responses that have dominated global discourse in the past weeks) will only reach a small proportion of the population.

In addition to gathering data on the population's existing technology, we may ask whether distributing additional technology is feasible. The red arrows in Tool 2, A-D indicate what one might reasonably assume to be possible. On of the author's ${ }^{3}$ earlier work with student teachers in Ghana showed that some students would acquire smartphones if there was a use for them. However, student teachers did not acquire smartphones as they were not used or required in college (in 2015 / 16). Nevertheless, this does not mean that a smartphone is within each teacher's economic means. The most likely extension is a wider use of existing technologies. In low-income settings, for instance, more students may try to acquire a radio or a non-smartphone while very few people will be able to afford a laptop.

In this context, we draw attention to a recent U.K. government announcement that laptops are being offered for online school lessons at home. ${ }^{4}$ In practice, the proposal distinguishes between different populations as the government will only offer laptops to some disadvantaged pupils:

\footnotetext{
${ }^{3}$ B.H.

${ }^{4}$ Citation: (^Coughlan, 2020), link: https://www.bbc.co.uk/news/education-52341596
} 
"Laptops or computer devices will be provided for some disadvantaged pupils in Year 10 - who will be taking their GCSEs next year. ... They will also be available to children with a social worker or those [children] leaving care."

The U.K. government will also provide a limited number of families with connectivity alongside the laptops:

"There is also the offer of some $4 G$ routers to help families connect to the internet."

At present, the specific number of available laptops has not been set:

"There is no specified number of laptops available, or set budget, and it will be up to schools or local authorities to decide who needs help with access to a computer.

This example shows that even in very high-income countries, laptop distribution is undertaken very cautiously. It is unlikely that low- and middle-income countries will be able to supply additional smartphones / laptops and connectivity at short notice to low-income populations. The provision of these devices is not only expensive and logistically complicated, but even if funding is made available, the necessary support to make these devices effective (training, supporting material, etc.), which is difficult at the best of times, cannot be delivered in a matter of months. Section 4 and Section 5 outline how governments can use low-tech solutions such as radio and television to deliver educational content during the current pandemic. 


\section{Organise your workforce}

We strongly recommend reviewing the organisation of the ministerial workforce, including how it can communicate with teachers, parents and institutional partners. While 'working from home' is an option in (very) high-income countries, it is not easy to implement in lowand middle-income countries. Staff are often not used to working from home, may not have adequate equipment or connectivity to work from home and may even suffer from infrastructural challenges, such as working time being limited by child care or government-mandated, rolling blackouts. 


\section{Tool 3. Organise your workforce}

\section{A. Ministry staff}

Create a core crisis team. Ensure that communication with this core team is possible and that they are set up with the necessary tools to work remotely during this crisis.

Open up communication channels and remote working for your workforce.

- Ensure communications between ministry workers and district officials. Consider what arrangements can be made to ensure working from home is effective.

- Get a toll-free phone number so that parents can text back (see below).

\section{B. Teachers}

Open up communication channels with your teachers. Organise ways to reach out to your teachers. Whether it's with SMS, Whatsapp, Telegram or email, determine a way of contacting teachers to put into place an immediate response. Headteachers can organise their teachers, and some teachers may be able to contact some or all of their students.

- Are most teachers likely to stay near their school or will they return to their families who may live elsewhere? Are there any groups of teachers who are more likely to remain within the schools' wider community?

- Consider whether one teacher could take responsibility for organising and monitoring remote learning for one group of students (e.g., one class or grade) throughout the week. This simplifies logistics. Give that teacher a way of contacting the parents of the children involved (e.g., through an SMS portal).

- Support your teachers with training and guidance.

Set up a help desk. Set up a toll-free phone number for teachers to call for support. This could be for pedagogical or IT-related issues.

\section{Parents}

Open up communication channels with parents. While not formally part of the workforce, parents can be the main point of contact with the student.

Set up a help desk. Set up a toll-free phone number for parents to call for support. This could be for pedagogical, IT-related issues or logistical support.

\section{Institutional partners}

Open up communication channels with partners working locally in education. These might include international or local NGOs, those working in education in emergencies, or private companies that could provide some support (e.g., EdTech companies, telecom providers). 


\section{Build a sense of community between students, families and materials schools \\ 5. Provide teaching and learning}

While we have listed 'building a sense of community' and 'provision of teaching and learning materials' separately, they are closely intertwined. Evidence from previous epidemics suggests that most children are unlikely to have the opportunity, skills or confidence to use self-study materials meaningfully - in print, on the radio or on TV - without the support of adults and of their peers. During the Ebola crisis in Sierra Leone, for example, most children did not benefit from broadcast media or print learning resources unless they had the support of their

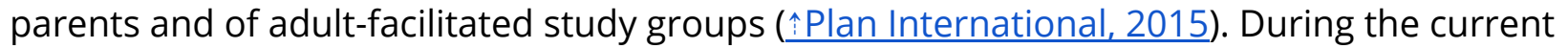
pandemic, teaching and learning materials could be used to provide a role for parents in the student learning experience at home. Similarly, materials may be developed that facilitate the collaboration of parents and teachers in ensuring that children receive tailored instruction. These sections are co-dependent and largely rely on what kind of technology is available. We separated these aspects because, more often than not, delivery of materials tends to take precedence. This is understandable, as centralised actions (e.g., broadcasting TV lectures) seem more tangible than distributed approaches (e.g., encouraging teachers to send WhatsApp messages to their students).

We emphasise the importance of adopting multi-pronged, sequenced strategies to address the educational impact of COVID-19. These strategies should reflect up-to-date education data (see Section 2) where possible. Even if you are confident that internet usage is high in some areas, you will still need to consider combining online learning with radio- or TV-based services to ensure those who cannot access the internet are not further marginalised. In particular, governments can use different modes of education delivery to support learning on other media channels (e.g., advertising existing online resources through radio and TV programming). Furthermore, while the immediate response may rely on some types of media, education providers need to expand their offering to other platforms as the crisis continues.

Below, we summarise the main mediums through which teaching and learning can take place, as well as how they could be reinforced and supplemented by other mediums. ${ }^{5}$ Please refer back to Tool 2 for the overall assessment of your national education system. Having reviewed the overall assessment, also consider how populations within your nation vary in wealth (Tool 2, Section E).

\footnotetext{
5 UUSAID (2020) recently published an evidence review on distance learning which is available at https://www.edu-links.org/sites/default/files/media/file/DELIVERING\%20DISTANCE\%20LEARNING\%20IN \%20EMERGENCIES.pdf.
} 


\section{Tool 4. Approaches for student learning under COVID-19}

\section{Approach 1. Radio}

Radio is an approach that serves low-income populations. This targets populations with no or very limited connectivity and limited technological resources (e.g., out-of-school children, refugees, students in rural areas; cf., Tool 2D, 2E).

\section{Description}

Ensuring learning
Education providers can adapt audio content from previous radio-based education initiatives (or from other countries; $\uparrow E D C, 2020$; link: PDF). The Ministry of Education should partner with national, commercial and community radio stations to deliver broadcasts across the country. Evidence from the Ebola crisis showed that a significant proportion of low-income populations did not have access to a radio or could not afford batteries (^Plan International, 2015). Accordingly, it may be necessary to ensure a supply of very low-cost radios

Alternatively, low-cost MP3 players can allow learners to access material anytime, without dependence on radio signals or broadcast times. Most low-cost phones can also act as MP3 players, for audio-files distributed on memory cards. In some countries, low-cost phones may have radio tuners built-in. Families may prefer to acquire a low-cost handset over a radio. However, there are challenges of distribution and support.

Evidence from the global learning crisis links 'chalk-and-talk-lecture-style' teaching to unacceptably low learning outcomes (Global Monitoring Report, 2015). Where it is the norm, children are often bored in school. It seems clear that 'chalk-and-talk-style' lectures broadcast via radio are also going to be ineffective. It is important to seek tried-and-tested content that at least stands a chance of improving learning outcomes.

We advise shifting from lectures broadcast via radio to interactive radio instruction. Content needs to be highly engaging and participatory, including songs and storytelling. It is imperative to engage with your students and produce programming that is both challenging and conducive to learning gains.

Evidence over several decades shows that interactive radio instruction is effective, but this is usually in contexts where an adult provides facilitation and support to groups of learners. During the Ebola crisis, learners in Sierra Leone were unable to benefit from radio instruction, even when provided with low-cost radios, unless they participated in study groups with adult facilitation (^Plan International, 2015). 


\begin{tabular}{|c|c|}
\hline $\begin{array}{l}\text { Curriculum } \\
\text { focus }\end{array}$ & $\begin{array}{l}\text { The limited duration of radio broadcasts means that the curriculum focus } \\
\text { needs to be chosen carefully. It appears that some areas (e.g., basic } \\
\text { literacy and reading) may be impossible to teach via broadcast } \\
\text { transmission. However, educators may be able to use storytelling and } \\
\text { songs to convey some basic numeracy. Moreover, storytelling and songs } \\
\text { may be able to provide students with much needed socio-emotional } \\
\text { support. Educators need to schedule radio lessons to deliver } \\
\text { developmentally appropriate content to targeted age groups. } \\
\text { When prioritising certain topics / subjects over others, educators need to } \\
\text { balance the effectiveness of teaching with the need for buy-in from } \\
\text { parents. While certain subjects / topics lend themselves better to radio, } \\
\text { there may also be subjects that are taken more seriously by parents and } \\
\text { students. Such 'higher stakes' subjects will encourage more engagement } \\
\text { from parents and students, and provide a semblance of educational } \\
\text { continuity. You should prioritise 'higher stakes' and effective subjects } \\
\text { now, and delay subjects that require more student-teacher interaction to } \\
\text { later stages. } \\
\text { A list of resources is available from UNHCR: How to ensure everyone can } \\
\text { continue learning amid the coronavirus situation. }\end{array}$ \\
\hline $\begin{array}{l}\text { Differentiation } \\
\text { and inclusion }\end{array}$ & $\begin{array}{l}\text { Content needs to be differentiated by age and learning achievement. You } \\
\text { should broadcast content for grade bands (e.g., grades 1-3, grades 4-6) } \\
\text { rather than for each grade to reduce the amount of required } \\
\text { programming. Instead of asking children to participate by grade, it may } \\
\text { be more appropriate to ask children to participate in lessons that reflect } \\
\text { their past academic achievement. } \\
\text { Children from marginalised communities may miss out as with other } \\
\text { distance learning approaches. A ^Plan International (2015) study on } \\
\text { radio-based education during the Ebola crisis noted that parents } \\
\text { prioritised keeping their children healthy and feeding their families over } \\
\text { listening to broadcasts. You need to address the most basic needs of } \\
\text { marginalised populations prior to implementing radio programming. } \\
\text { It is important to recognise language diversity and local-language } \\
\text { programming needs to be available, especially for primary school grades. } \\
\text { Many children around the world are taught in a language they don't } \\
\text { speak or understand. Teachers try to overcome this by repeating } \\
\text { instructions, checking understanding, or switching languages. Without } \\
\text { similar care, broadcast media may further marginalise children from } \\
\text { disadvantaged communities. Many learners need the support of an adult } \\
\text { who can mediate between the broadcast media and the learners' pace of } \\
\text { learning and mother tongue. Local study groups, with adult facilitation, } \\
\text { are one way of providing this support. Where full, local-language } \\
\text { programming is not possible, some local-language segments should be }\end{array}$ \\
\hline
\end{tabular}




\begin{tabular}{|c|c|}
\hline & 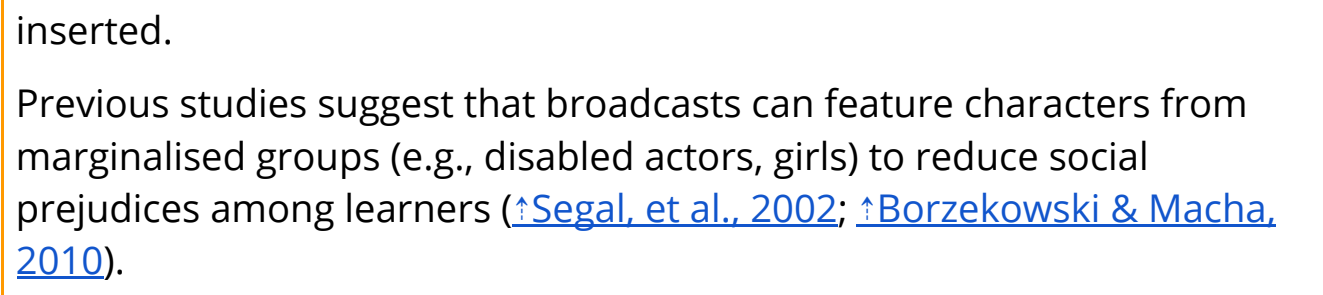 \\
\hline $\begin{array}{l}\text { Supplemented } \\
\text { by }\end{array}$ & How \\
\hline SMS & $\begin{array}{l}\text { SMS messages can be sent through government or NGO-operated SMS } \\
\text { portals. SMS messages can also be sent by mobile network operators. } \\
\text { Parents and carers should be able to register by responding to the initial } \\
\text { message (In local language: "Are you a parent or caregiver of a school-age } \\
\text { child? Please reply to this message if you are and you will be subscribed to } \\
\text { the government messages on your national education response. You do not } \\
\text { need to include any text, simply replying will be sufficient. Call XXX to hear a } \\
\text { spoken version."). } \\
\text { SMS messages could serve these purposes: } \\
\text { - inform and remind parents / community members of broadcasting } \\
\text { schedules, offering instructions on how their children will benefit from } \\
\text { programming; } \\
\text { - send caregivers practical suggestions on cost-free learning exercises } \\
\text { to integrate into their daily routines; } \\
\text { - provide students with supplementary content such as recaps, optional } \\
\text { homework exercises and quizzes; } \\
\text { - raise parental awareness of important health messages and child } \\
\text { safeguarding information; } \\
\text { - allow teachers to contact students (when possible) to monitor } \\
\text { progress and well-being. }\end{array}$ \\
\hline Radio & $\begin{array}{l}\text { Many nations have successful talk-radio stations. Awareness of } \\
\text { education-focussed radio could be raised by phone-in shows or by radio } \\
\text { programming that invites students, parents and specialists to discuss } \\
\text { educational content. }\end{array}$ \\
\hline Phone & $\begin{array}{l}\text { Free Phone chat lines established to respond to feedback and queries } \\
\text { from caregivers. }\end{array}$ \\
\hline $\begin{array}{l}\text { Teacher / } \\
\text { volunteer visits }\end{array}$ & $\begin{array}{l}\text { Even with social distancing, it may be possible for teachers, facilitators or } \\
\text { community volunteers to visit students who live locally, particularly } \\
\text { students who may be marginalised. }\end{array}$ \\
\hline
\end{tabular}




\begin{tabular}{|c|c|}
\hline $\begin{array}{l}\text { Options for } \\
\text { sequencing }\end{array}$ & How and when \\
\hline Interactive voice & $\begin{array}{l}\text { Some nations already operate interactive voice services. We recommend } \\
\text { exploring these services to see how they can enhance radio broadcasts. } \\
\text { If you have organisations offering interactive voice services at a national } \\
\text { or regional level already, you should discuss options for using the service. }\end{array}$ \\
\hline Print materials & $\begin{array}{l}\text { Your nation may or may not have appropriate materials already. You } \\
\text { should seek advice from education experts to explore the extent to } \\
\text { which you may be able to supplement your existing print materials with } \\
\text { Open Educational Resources. You need to consider print materials for: } \\
\text { - students (e.g., workbooks or newspaper supplements with } \\
\text { content to revise, and exercises to complete); } \\
\text { - caregivers and parents (e.g., written guidance on how to facilitate } \\
\text { interaction with media content); } \\
\text { - teachers; } \\
\text { - headteachers and district officers. }\end{array}$ \\
\hline
\end{tabular}




\section{Approach 2. TV}

TV is an approach that serves middle-income populations. This targets populations with a high availability of TV but with internet access ranging from limited to none. It may be that lower-income populations also have access through 'communal watching', although children will only benefit from this if programming is interesting and engaging for the wider community.

\begin{tabular}{|c|c|}
\hline Description & $\begin{array}{l}\text { The Ministry of Education launches one or more dedicated educational } \\
\text { channels or designates time-slots within existing channels as 'school } \\
\text { zones'. Educational videos are delivered - avoiding regular } \\
\text { talk-and-chalk-style videos, and focusing on high-quality educational } \\
\text { programming (e.g., Sesame Street, Ubongo Kids, documentaries, etc.). } \\
\text { As many households would only have one TV - and there may also be } \\
\text { significant low-income populations in the same nation - you will have to } \\
\text { provide radio in parallel. Even where a TV is in the household, if there is } \\
\text { more than one child in the household, parallel radio and TV is necessary. } \\
\text { The approach can be enhanced by shifting from broadcast TV to } \\
\text { interactive TV instruction. Low-cost mobile phones are often also able to } \\
\text { play video content distributed on memory cards However, distribution } \\
\text { and support remains a challenge. }\end{array}$ \\
\hline $\begin{array}{l}\text { Ensure } \\
\text { learning }\end{array}$ & $\begin{array}{l}\text { As we noted in the radio section above, chalk-and-talk (i.e., lecture-style) } \\
\text { teaching has been linked to unacceptably low learning outcomes, thought } \\
\text { to have resulted in the global learning crisis. It thus seems clear that } \\
\text { 'chalk-and-talk-style' lectures broadcast via TV are going to be ineffective. } \\
\text { It is important to seek tried-and-tested content that at least stands a } \\
\text { chance of positively affecting learning outcomes. We expect such content } \\
\text { to be highly engaging for children. Such programming includes interactive } \\
\text { programming such as Sesame Street (and the various regional and } \\
\text { localised versions), and Ubongo Kids. }\end{array}$ \\
\hline $\begin{array}{l}\text { Curriculum } \\
\text { Focus }\end{array}$ & $\begin{array}{l}\text { As we noted in the radio section, broadcasts are inherently limited; } \\
\text { however, TV is clearly more versatile than radio and allows greater } \\
\text { curriculum coverage. As with radio, in prioritising certain topics / } \\
\text { subjects over others, there has to be a balance between effectiveness of } \\
\text { teaching and buy-in from parents. However, with TV it's easier to focus on } \\
\text { core subjects (e.g., literacy and numeracy). We recommend that } \\
\text { programming should first focus on a limited number of core subjects and } \\
\text { deliver those well, rather than trying to cover too many subjects. Given } \\
\text { that households are likely to only have one TV, or at least fewer TVs than } \\
\text { children, programming may need to be scheduled based on different age }\end{array}$ \\
\hline
\end{tabular}




\begin{tabular}{|c|c|}
\hline & $\begin{array}{l}\text { groups and academic levels. In this context, TV use may need to alternate } \\
\text { with radio. }\end{array}$ \\
\hline $\begin{array}{l}\text { Differentiation } \\
\text { and inclusion }\end{array}$ & $\begin{array}{l}\text { Content needs to be differentiated by age and learning achievement. } \\
\text { Rather than asking children to participate by grade, it may be more } \\
\text { appropriate to ask children to participate based on their prior } \\
\text { achievement. } \\
\text { It is important to recognise language diversity and local language } \\
\text { programming needs to be available, especially for primary school grades. } \\
\text { Where full local language programming is not possible, some local } \\
\text { language segments should be inserted. } \\
\text { As with all approaches, children in marginalised communities may miss } \\
\text { out. Children are more likely to be allowed to watch educational content if } \\
\text { it is also entertaining or engaging for the wider family or community, } \\
\text { particularly where TV is viewed communally. } \\
\text { TV offers opportunities for users who have an auditory disability } \\
\text { (including profound deafness). TV programming should therefore make } \\
\text { use of sign language. It has been argued that subtitles are helpful for all } \\
\text { watchers and all programming should be transmitted with subtitles. }\end{array}$ \\
\hline $\begin{array}{l}\text { Supplemented } \\
\text { by }\end{array}$ & How \\
\hline SMS & $\begin{array}{l}\text { SMS messages can be sent through government or NGO-operated SMS } \\
\text { portals. SMS messages can also be sent by mobile network operators. } \\
\text { Parents and carers should be able to register by responding to the initial } \\
\text { message (In local language: "Are you a parent or caregiver of a school-age } \\
\text { child? Please reply to this message if you are and you will be subscribed to the } \\
\text { government messages on your national education response. You do not need } \\
\text { to include any text, simply replying will be sufficient. Call XXX to hear a spoken } \\
\text { version."). } \\
\text { SMS messages could serve these purposes: } \\
\text { - inform and remind parents / community members of broadcasting } \\
\text { schedules, offering instructions on how their children will benefit from } \\
\text { programming; } \\
\text { - send caregivers practical suggestions on cost-free learning exercises to } \\
\text { integrate into their daily routines; } \\
\text { - provide students with supplementary content such as recaps, optional } \\
\text { homework exercises and quizzes; } \\
\text { - raise parental awareness of important health messages and child } \\
\text { safeguarding information; }\end{array}$ \\
\hline
\end{tabular}




\begin{tabular}{|c|c|}
\hline & $\begin{array}{l}\text { - allow teachers to contact students (when possible) to monitor progress } \\
\text { and well-being. }\end{array}$ \\
\hline Radio & $\begin{array}{l}\text { Many nations have successful talk-radio stations. Awareness of } \\
\text { education-focussed radio could be raised by phone-in shows or by radio } \\
\text { programming that invites students, parents and specialists to discuss } \\
\text { educational content. }\end{array}$ \\
\hline Internet & $\begin{array}{l}\text { Teachers (when possible) reach out to their students with instructions } \\
\text { and regular check-ins. } \\
\text { When possible, all programming broadcast via TV or radio are made } \\
\text { available online on a zero-bandwidth-cost government website. }\end{array}$ \\
\hline $\begin{array}{l}\text { Options for } \\
\text { sequencing }\end{array}$ & How and when \\
\hline Interactive voice & $\begin{array}{l}\text { As for radio. In some nations, interactive voice services are already } \\
\text { operated. We recommend exploring those services and see how they can } \\
\text { enhance TV. }\end{array}$ \\
\hline Print materials & $\begin{array}{l}\text { As for radio. Students receive workbooks or newspaper supplements } \\
\text { with content to revise and exercises to complete. Caregivers offered } \\
\text { written guidance on how to best facilitate interaction with media content. } \\
\text { Your nation may or may not have appropriate materials already; you } \\
\text { should seek advice from education experts to explore to what extent you } \\
\text { may be able to supplement your existing print materials with Open } \\
\text { Educational Resources. You need to consider print materials not only for } \\
\text { students, but also for teachers and parents as well as others within the } \\
\text { education system, such as headteachers and district officials. }\end{array}$ \\
\hline Online materials & $\begin{array}{l}\text { TV programming and radio programming can be used to draw attention } \\
\text { to online learning materials. }\end{array}$ \\
\hline
\end{tabular}




\section{Approach 3. Basic digital and online}

\section{Basic online is an approach that serves high-income populations.}

Populations with widespread but limited access to the internet. (e.g., a child has 15-30 minutes of access a day on their parent's smartphone, approximately $60 \%$ smartphone availability).

\begin{tabular}{|c|c|}
\hline Description & $\begin{array}{l}\text { In many countries, basic digital resources should be seen as an important } \\
\text { but supplementary approach. Digital resources would usually be } \\
\text { transmitted over the internet. Such materials should be made available } \\
\text { on a zero-bandwidth-cost website. }{ }^{6} \text { For populations living in close } \\
\text { proximity (such as refugees in a refugee camp) it may be possible to } \\
\text { distribute content via local WiFi hotspots (e.g., using Kolibri). } \\
\text { We cannot overemphasise that it is imperative to have a set of } \\
\text { well-structured resources that engage students, and extend learning in an } \\
\text { appropriately challenging way. } \\
\text { If devices - and potentially the internet - are available to students in } \\
\text { some form, then surely they are available to teachers. The Ministry of } \\
\text { Education must engage with teachers (see 'Organise your workforce') to } \\
\text { provide guidance on how to connect with pupils as well as on } \\
\text { asynchronous remote teaching (e.g., PDF guide / video / online course). } \\
\text { This guidance can be distributed via social media and a } \\
\text { zero-bandwidth-cost website. } \\
\text { Teachers should connect with their students on WhatsApp / Telegram } \\
\text { each day, but on a limited basis (e.g., two check-ins, with daily } \\
\text { instructions). Voice notes, images and written messages can be shared } \\
\text { between teachers and students. }\end{array}$ \\
\hline $\begin{array}{l}\text { Ensure } \\
\text { learning }\end{array}$ & $\begin{array}{l}\text { Time should be used for engaging and interactive activities rather than } \\
\text { watching 'chalk-and-talk' lectures. Smartphones offer two advantages } \\
\text { over TV and radio. Firstly, apps can quickly respond to children's answers } \\
\text { and offer individualised learning. This is particularly useful for basic-skills } \\
\text { (see below). Secondly, smartphones offer an opportunity for two-way } \\
\text { communication, between educator and learner, or between groups of } \\
\text { learners. In situations where most learners or caregivers do not have } \\
\text { access to smartphones, teachers may have such devices. WhatsApp } \\
\text { groups can allow coordination between teachers and caregivers. For } \\
\text { example, teachers and caregivers can share ideas for learning activities } \\
\text { that can be copied out and distributed on paper or by word of mouth, in } \\
\text { local communities. }\end{array}$ \\
\hline
\end{tabular}

\footnotetext{
${ }^{6}$ Zero-bandwidth-cost websites are sites that do not take up any of users' monthly data plans. These can be negotiated with telecom providers.
} 


\begin{tabular}{|c|c|}
\hline $\begin{array}{l}\text { Curriculum } \\
\text { focus }\end{array}$ & $\begin{array}{l}\text { These activities should initially focus on learning objectives that cannot be } \\
\text { achieved through interactive TV and radio. For example, smartphones } \\
\text { appear to be better placed for basic literacy (phonics) than interactive TV } \\
\text { and radio. Smartphones also lend themselves to 'drill-type' activities, such } \\
\text { as learning times tables. Even where it is possible to teach certain topics } \\
\text { via TV / radio, digital activities are advantageous in certain areas, such as } \\
\text { hard-to-learn topics in mathematics. }\end{array}$ \\
\hline $\begin{array}{l}\text { Differentiation } \\
\text { and inclusion }\end{array}$ & $\begin{array}{l}\text { Most children in low- and middle-income countries will not have access to } \\
\text { online learning during or immediately after the COVID crisis. } \\
\text { While online learning has many advantages, it also has its limits: Users are } \\
\text { using small screens, may not have good connectivity etc., which may } \\
\text { cause issues with inclusion. } \\
\text { However, there are clear strengths to digital approaches that can increase } \\
\text { inclusion and may allow learning to be better tailored to students, } \\
\text { especially where those students have come far off their learning } \\
\text { trajectory. } \\
\text { All materials need to meet accessibility standards (including both access } \\
\text { for users with disabilities as well as low-bandwidth accessibility). }\end{array}$ \\
\hline $\begin{array}{l}\text { Supplemented } \\
\text { by }\end{array}$ & How \\
\hline Radio & $\begin{array}{l}\text { Many nations have successful talk-radio stations. Awareness of } \\
\text { government educational websites could be raised by phone-in shows or } \\
\text { by radio programming that invite students, parents and specialists to } \\
\text { discuss educational content. } \\
\text { Radio programming to be made available to those with no TV / internet } \\
\text { access. (see Approach 1). }\end{array}$ \\
\hline TV & $\begin{array}{l}\text { TV programming to be made available to supplement limited internet } \\
\text { connectivity (see Approach 2). }\end{array}$ \\
\hline $\begin{array}{l}\text { Options for } \\
\text { sequencing }\end{array}$ & How and when \\
\hline Print materials & $\begin{array}{l}\text { As for radio and TV. Students receive workbooks or newspaper } \\
\text { supplements with content to revise, and exercises to complete. } \\
\text { Caregivers offered written guidance on how to best facilitate interaction } \\
\text { with media content. }\end{array}$ \\
\hline
\end{tabular}




\begin{tabular}{|c|c|}
\hline \multicolumn{2}{|c|}{$\begin{array}{l}\text { Extended online is an approach that serves very high-income } \\
\text { populations. Populations with reasonable access to the internet and good } \\
\text { device availability in the household, including some laptops. }\end{array}$} \\
\hline Description & $\begin{array}{l}\text { Extended digital access is seen as very desirable, but there are many } \\
\text { steps that need to fall into place. Even in very high-income countries, } \\
\text { extensive use of digital resources online has been problematic. More } \\
\text { common solutions have included WhatsApp groups for coordination } \\
\text { among teachers and parents. } \\
\text { If you are planning a large online offering, you should first consider } \\
\text { which populations have access to this service. If you have a large } \\
\text { low-income population in your nation, we suggest a radio-first or TV-first } \\
\text { approach. } \\
\text { If you are using an extensive online approach, it is imperative to have a } \\
\text { set of well-structured resources that engage students and extend } \\
\text { learning in an appropriately challenging way. This should include } \\
\text { interactive applications such as GeoGebra, block-coding, games, etc. } \\
\text { You must also carefully plan your scheme of work, ensuring curriculum } \\
\text { alignment of the various resources utilised, as well as ensuring that you } \\
\text { are covering as much of the curriculum as possible. }\end{array}$ \\
\hline
\end{tabular}




\section{Prepare for what happens after the COVID-19 pandemic}

While the immediate response to the pandemic is critical, it should not come at the expense of attempting to mitigate medium- and long-term implications of the crisis. After an extended break from formal learning, students will return to schools with gaps in their knowledge. It is likely that students will not have equally benefited from the various remote learning approaches. In more extreme cases, students may not even return to school, as they may have been socialised into generating income for their families while away from school.

\begin{tabular}{|l|l|l|}
\hline \multicolumn{2}{|c|}{ Medium-term impact of the COVID-19 pandemic } \\
\hline \multicolumn{1}{|c|}{ Schooling lag } & \multicolumn{1}{|c|}{ Performance gaps } & Student retention \\
\hline $\begin{array}{l}\text { Students will return to the } \\
\text { classroom having missed } \\
\text { months of schooling }\end{array}$ & $\begin{array}{l}\text { Students will benefit from } \\
\text { remote learning efforts to } \\
\text { varying degrees }\end{array}$ & $\begin{array}{l}\text { Some students may not } \\
\text { return to school after such } \\
\text { a long break }\end{array}$ \\
\hline
\end{tabular}

Firstly, we emphasise the need to continue using the interventions made during the pandemic where they make sense. For example, if phone numbers of parents have been collected to stay in touch, this database should be continued to be used (e.g., to follow up where children are absent); where good TV programming with sign-language has been introduced, we should continue using it.

Moreover, we know that many education systems in low- and middle-income countries are already struggling (the so-called 'global learning crisis'). Rather than just focussing on the medium-term impact, the biggest gains would be to use the current pause to prepare for reform (see Continue or reboot? Overarching options for education responses to COVID-19 in low- and middle-income countries). We therefore ask whether it may be possible in your nation to use the pandemic period to systematically improve quality ahead of schools reopening?

There will probably be at least 6 months (and perhaps up to 12 months) before schools can reopen. It may be possible to use that time to introduce systematic reform to improve teaching and learning quality. For example, it may be possible to make arrangements for learning resources for all children (such as textbooks and other learning materials) and to plan a national teacher professional development programme ( $\uparrow$ Haßler, 2020; ^ Haßler \& Moss, 2020; ^Haßler, 2020). 


\section{References}

A full list of links and references can be found on the EdTech Hub's Evidence Library.

Borzekowski, D. L. G., \& Macha, J. E. (2010). The role of Kilimani Sesame in the healthy development of Tanzanian preschool children. Journal of Applied Developmental Psychology, 31(4), 298-305. https://doi.org/10/dfharx

Coflan, C. M., \& Kaye, T. (2020). Using education technology to support learners with special educational needs and disabilities in low-and middle-income countries (EdTech Hub Helpdesk Response No. 4). EdTech Hub. https://doi.org/10.5281/zenodo.3744581

Coughlan, S. (2020, April 19). Laptops offered for online school lessons at home. BBC News. https://www.bbc.com/news/education-52341596

David, R., Pellini, A., Jordan, K., \& Philips, T. (2020). Education during the COVID-19 crisis: Opportunities and constraints of using EdTech in low-income countries. Zenodo. https://doi.org/10.5281/zenodo.3750976

Global Monitoring of School Meals During COVID-19 School Closures. (n.d.). Retrieved 19 April 2020, from https://cdn.wfp.org/2020/school-feeding-map/index.html

Haßler, B. (2020a). Teacher professional development and coaching in low-income countries: Overarching considerations for the use of technology (EdTech Hub Helpdesk Response No. 2). EdTech Hub. https://doi.org/10.5281/zenodo.3631747

Haßler, B. (2020b). Teacher professional development and coaching in low-income countries: Practical considerations for the use of technology. (EdTech Hub Helpdesk Request No. 3). EdTech Hub. https://doi.org/10.5281/zenodo.3631749

Haßler, B. (2020c, April 16). Continue or reboot? Overarching options for education responses to COVID-19 in low- and middle-income countries. Open Development \& Education. https://opendeved.net/2020/04/16/continue-or-reboot/

Haßler, B., \& Moss, C. (2020). Teacher professional development and coaching in low-income countries: An evidence-informed conversation (EdTech Hub Helpdesk Response No. 1). EdTech Hub. https://doi.org/10.5281/zenodo.3631745

Malpass, D. (2020). Remarks by World Bank Group President David Malpass on G20 Finance Ministers Conference Call on COVID-19. World Bank. Retrieved 19 April 2020, from https://www.worldbank.org/en/news/speech/2020/03/23/remarks-by-world-bank-grouppresident-david-malpass-on-g20-finance-ministers-conference-call-on-covid-19

Montsho, M. (2020, April 17). High Court stops Malawi's 21-day coronavirus lockdown. https://www.iol.co.za/news/africa/high-court-stops-malawis-21-day-coronavirus-lockdow $\underline{n-46851304}$

Plan International. (2015). Ebola: Beyond the health emergency (p. 211). Plan International. https://www.plan.ie/wp-content/uploads/2015/03/GLO-Ebola-Final-IO-Eng-Feb15.pdf 
Psaki, S. R., McCarthy, K. J., \& Mensch, B. S. (2018). Measuring Gender Equality in Education: Lessons from Trends in 43 Countries. Population and Development Review, 44(1), 117-142. https://doi.org/10.1111/padr.12121

Ramanaik, S., Collumbien, M., Prakash, R., Howard-Merrill, L., Thalinja, R., Javalkar, P., Murthy, S., Cislaghi, B., Beattie, T., Isac, S., Moses, S., Heise, L., \& Bhattacharjee, P. (2018). Education, poverty and 'purity' in the context of adolescent girls' secondary school retention and dropout: A qualitative study from Karnataka, southern India. PLOS ONE, 13(9). https://doi.org/10.1371/journal.pone.0202470

Richmond, S. (2020). Repurposing Established Radio and Audio Series to Address the COVID-19 Educational Crises. Education Development Trust. https://www.edc.org/sites/default/files/Repurposing-Established-Radio-Audio-Series.pdf

Segal, L., Cole, C. F., \& Fuld, J. (2002). Developing an HIV/AIDS Education Curriculum for Takalani Sesame, South Africa's Sesame Street. Early Education \& Development, 13(4), 363-378. https://doi.org/10/fhjtsf

UNESCO Institute for Statistics. (2015). Information and Communication Technology (ICT) in Education in sub-Saharan Africa: A comparative analysis of basic e-readiness in schools. Information Paper No. 25. UNESCO Institute for Statistics. https://doi.org/10.15220/978-92-9189-178-8-en

USAID. (2020). Delivering Distance Learning in Emergencies: A review of evidence and best practice. https://www.edu-links.org/sites/default/files/media/file/DELIVERING\%20DISTANCE\%20LEA RNING\%20IN\%20EMERGENCIES.pdf 